in vivo $35: 3031-3037(2021)$

doi:10.21873/invivo. 12598

Review

\title{
Lipomatous Meningioma: Clinical-Pathological Findings, Imaging Characterisation and Correlations of a Rare Type of Meningioma
}

\author{
PIERFRANCESCO LAPOLLA ${ }^{1}$, PIETRO FAMILIARI ${ }^{2}$, GIUSEPPA ZANCANA ${ }^{2}$, PLACIDO BRUZZANITI ${ }^{2}$, \\ RUI CHEN ${ }^{3}$, XIAOBO LI ${ }^{3}$, GIUSEPPE FAMILIARI ${ }^{1}$ and ANTONIO SANTORO ${ }^{2}$ \\ ${ }^{1}$ Department of Anatomy, Histology, Forensic Medicine and Orthopaedics', \\ Sapienza University of Rome, Rome, Italy; \\ ${ }^{2}$ Department of Human Neurosciences, Division of Neurosurgery, \\ Policlinico Umberto I University Hospital, Sapienza, University of Rome, Rome, Italy; \\ ${ }^{3}$ Department of Environmental Medicine and Toxicology, Southeast University, Nanjing, P.R. China
}

\begin{abstract}
Lipomatous meningioma (LM) is a form of metaplasia, originating from intracellular lipid bodies accumulation due to metabolic alterations. A comprehensive literature review was performed introducing further elements of evaluation. The parameters utilized were age, sex, location, clinical presentation, imaging features, treatment, and recurrences. Seizure and headache are the primary onsets of symptoms. Further LM clinical features, such as visual disturbances and visual epileptic seizures were examined. Symptoms may occur ten years prior to LM finding and it can resolve completely with the indicated surgery. LM computed tomography imaging analysis reveals hypodense regions due to the presence of fat content. On magnetic resonance imaging, the lesion displays hyperintense signal in T1-T2 with signal loss in the fatsuppression sequences. Immunohistochemically, lipidized meningioma cells are positive for Epithelial-Membrane Antigen, Vimentin, CD99, S-100 protein, and progesterone receptor. The recurrence risk rate of $L M$ is estimated to be around $17 \%$. Precise immune-histological findings have been
\end{abstract}

This article is freely accessible online.

Correspondence to: Pierfrancesco Lapolla, Department of Anatomy, Histology, Forensic Medicine and Orthopaedics, Sapienza University of Rome, Via Alfonso Borelli 5, 00161 Rome, Italy. Tel: +393488034275, e-mail: lapolla.1526391@studenti.uniroma1.it

Key Words: Lipomatous meningiomas, tumour, meningioma, imaging, seizure, headache, review. correlated with imaging features to help with early diagnosis. A defined diagnosis of LM is a crucial factor in the choice of treatment.

Meningiomas are the most common benign intracranial tumours, accounting for $36 \%$ of all central nervous system (CNS) neoplasms. Their incidence, increasing with age, remarkably rises after the age of 65. Meningiomas are approximately twice as common in females than males and are estimated to be three times more common in females of the 35 to 54 years old age group. Meningiomas are tumours of mesodermal origin, thought to grow from the arachnoid cap cells of the arachnoid villi and granulations. According to the 2016 World Health Organization (WHO) classification scheme, they are classified into three groups: grade I (benign), grade II (atypical), and grade III (anaplastic). Approximately $80 \%$ of meningiomas are WHO grade I. Surgery, aiming at gross total resection (GTR), is the treatment of choice for symptomatic WHO grade I meningiomas. WHO classification of CNS tumors stratifies grade I meningiomas into: (a) meningothelial, (b) fibrous (fibroblastic), (c) transitional (mixed), (d) psammomatous, (e) angiomatous, (f) microcystic, (g) secretory, (h) lymphoplasmacytic-rich, and (i) metaplastic (1). According to Kasantikul et al. (2), this diversity may be related to the capability of arachnoidal cap cells to undergo de-differentiation, thus transforming into different mesenchymal cell types (2). Lipomatous metaplasia is an infrequent and rare histological finding. The first case described was the one described by Bailey and Bucy in 1931 (3). Since then, a total of 64 cases have been reported in the literature. Other elements from our case, here reported, aimed 
at contributing to the current knowledge of this rare pathology in terms of differential diagnosis and prognosis.

\section{Literature Review}

In the literature, we have reviewed and collated all the cases reported to date of lipomatous meningioma in the last 35 years. The terms used for the PubMed database search were "Lipomatous" and "Lipoblastic meningioma". Xanthomatous meningiomas, cutaneous neurofibromas, and liponeurocytoma were excluded from the search. Initially, 52 manuscripts were found and evaluated. Records identified from reviewed references were examined and resulted in further 154 manuscripts. The inclusion parameters were age, sex, onset and duration of symptoms, imaging characteristics [computed tomography (CT) and magnetic resonance imaging (MRI)], treatment, histology, immunohistochemistry, and follow-up. In total, we have selected 64 cases of lipomatous meningioma. The selection process is illustrated in Figure 1, using the Prisma Flow Diagram.

Ethical approval. Institutional review board/ethics committee approval was not required for this study. All procedures performed in the studies involving human participants were in accordance with the ethical standards of the institutional and/or national research committee and with the 1964 Helsinki Declaration and its later amendments or comparable ethical standards.

\section{Discussion/Observations}

Pathophysiology. Lipomatous meningiomas are benign lesions, World Health Organization (WHO) grade1, with a good prognosis. According to the WHO 2007 classification of meningiomas, it is considered a subtype of metaplastic meningioma, and includes tumors that contain different types of mesenchymal cells able to differentiate into different subtypes (metaplastic changes), including fat cells (4). Metaplastic differentiation commonly occurs in some subtypes of meningiomas such as meningothelial, transitional, and fibrous (5). Specifically, these types of meningioma contain meningothelial cells that resemble adipocytes or lipoblasts (6). The terms lipoblastic or lipomatous meningioma were used to refer to this type of meningioma. In 2003, Bolat et al. coined the term "lipidised" to indicate all meningiomas with those characteristics typical of lipomatous meningiomas. We have analysed 64 cases to perform a literature review and to understand the characteristics of lipomatous meningiomas better. Our study revealed that fat accumulation occurs mainly in meningiomas of the meningothelial and transitional types (7). These neoplasms contain a mixture of meningothelial-type cells and cells with a predominant adipocyte tissue type. In the literature, we have found four cases of the secretory meningioma type with a lipomatous component. Yamada et al. reported the first case in 1999 (8), the second one by Matyia et al. in 2005 (9), the third one by Patil et al. in 2017 (10), and the last one by Khubrani et al. in 2019 (11). Secretory type meningioma can be the result of the transformation into the secretory form by meningothelial cells; the underlying mechanism involves the altered glycosylation of the tumour cells (12). In the past, it was assumed that fat accumulation in meningioma was due to metaplastic alteration of meningothelial cells (13). However, recent studies demonstrate that lipids' accumulation is due to a metabolic abnormality of the tumour cells rather than true metaplasia $(14,15)$. The proportion of adipocyte component varies from $10 \%$ to $90 \%$ $(7,16,17)$. The cytoplasm of the lipidated tumour cells contains large fat droplets; nuclei are shifted to the periphery and composed mainly of triglycerides (18). These characteristics differentiate the lipomatous meningioma from the xanthomatous meningiomas in which they present central nuclei mostly composed of cholesterol (19). Also, lipid cells contain common cytoplasmic elements, interdigitated cellular processes, and desmosomes (16). Other differential diagnoses include liposarcoma, chondroma, metastatic mucinous carcinomas, giant cell glioblastomas, and epidermoid cysts.

\section{Clinical Presentation}

Like most subtypes of meningiomas, lipomatous meningioma most frequently affects women rather than men. Symptoms are related to the meningioma's size and location; similarly, to other meningiomas subtypes, seizures and headache are the main onset symptoms. Seizures are most likely associated with tumours located in the frontal and temporal areas, whereas headaches with parietal tumours $(6,15)$. Almost all intracranial lipomatous meningiomas occur in the supratentorial location with frontal and parietal areas as the most common sites. In our presented case and the one of Okamoto et al., the lesion's implantation was on the tentorium (20). Roncaroli et al. and De Eulate-Beramend et al. reported three cases in the spinal location. Kasantikul et al. reported a case of LM correlated with an arteriovenous (AVM) malformation (2); according to the author, the presence of the coexistence of the AVM and meningioma, was explained by the chronic irritation of the arachnoid cells, which can then stimulate the growth of meninges lesions (21).

In the case reported by Kasantikul et al. (2), symptoms manifestation such as headache and seizures were related to the angioma rupture as suggested by the findings of erythrocytes and hemosiderin in the tissue surrounding the meningioma. Kashimura et al. described a temporal lipomatous meningioma, which was initially treated conservatively. This meningioma was bleeding in the subdural space, leading to the formation of subdural hematoma. The hypothesis of the bleeding was attributed to 

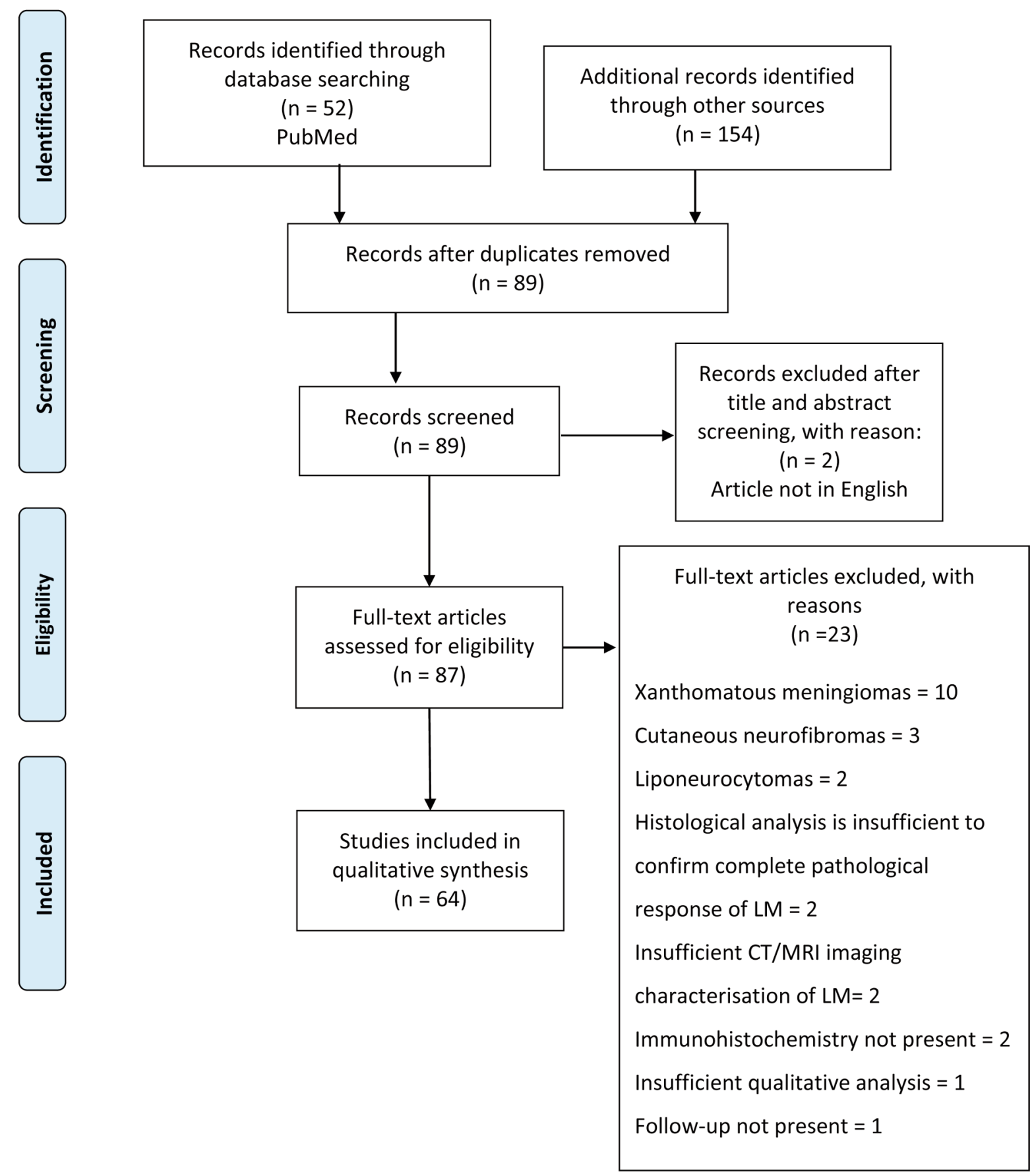

Figure 1. Flow chart of the work selection process.

the rupture of abnormal vessels. They developed in the tumour mass comprising capillaries and venules with walls of different thickness, which constituted the tumor's vascular network (22). Kimwada et al. analysed a woman of 74 years affected by a renal cell carcinoma that metastasised and developed in a lipomatous meningioma; the lesion was composed of a central portion of metastasised tissue originating from the renal carcinoma and a peripheral portion consisting of microcystic meningioma tissue with focal lipomatous metaplasia (23). 


\section{Assessment and Diagnosis}

Patients analysed in this review are in the range of 14 and 90 years old, with an average of 57 years. Forty patients were female; the patients' total ratio was $\mathrm{M}: \mathrm{F}=1: 2$. Duration from symptoms onset to treatment-outcome spanned from 10 years to 10 days. Onset of symptoms were mainly headache in $34 \%(n=22)$ of the cases (total cases $\mathrm{n}=64)$ and epileptic seizure in $36 \%(\mathrm{n}=23)$, followed by visual disorders $11 \%(n=7)$, hemiparesis $9 \%(n=6)$, and gait instability $6 \%(n=4)$. Less frequent symptoms such as behavioural disorders suggestive of a frontal lesion, memory loss, and confusion, each accounted for $5 \%(n=3)$, and other minor symptoms included muscle such as weakness, spinal cord compression, attention deficit, and dysphasia, each found in $3 \%(n=2)$. Six percent of the cases $(n=4)$ was accidentally detected on imaging investigations (Table I).

At CT imaging, traditional meningiomas appear as solid extra-axial lesions with dura attachment; they present density similar to the cerebral parenchyma with homogeneous contrast enhancement. Lipomatous meningiomas show a hypodensity appearance because the fat tissue component has attenuation values between -50 and -100 Hounsfield Unit (H.U.) (24). When the adipose component is abundant, the lesions present a hyperintense signal in the $\mathrm{T} 1$ weighted images and $\mathrm{T} 2$ weighted with signal loss in the sequences with fat suppression. If the adipose component is less predominant, the signal is isointense in $\mathrm{T} 1$ and $\mathrm{T} 2$ (25). The contrast enhancement is homogeneous. Oedema is not ordinarily present. The presence of oedema is a sign of parenchymal tumour invasion. However, oedema can be related to the vascular endothelial growth factor (VEGF) production by meningothelial cells in the case of specific subtypes of meningiomas (e.g., secretory) with the absence of parenchymal tumour invasion (15). Perfusion-weighted Magnetic Resonance imaging (PWI-MR) performed on a case of lipomatous meningioma shows an unusual hypovascularisation of the lesion demonstrated by the extremely low levels of relative cerebral blood volume (rCBV) (26). Colnat-Coulbois et al. reported a case of temporal lipomatous meningioma with hyperostosis of the large sphenoid wing (27). Kim et al., instead, reported the case of a 49-year-old man with a parietal lipomatous meningioma with an erosion of the internal boarding of the bone (6). Intraoperatively, the tumour has well-defined margins and a brown-yellowish appearance, with a visible adipocyte component. Histologically, it is composed of adipocyte-like cells within a conventional type meningioma (11). These adipocyte-like cells are elongated with tapered ends and round nuclei with eosinophilic cytoplasm. Mitotic index is very low, the Ki67 marker for proliferation rate shows values less than $1 \%$ (6). Immunohistochemically, lipidated meningioma cells are reactive for epithelial membrane antigen (EMA), Vimentin
Table I. Lipomatous meningioma associated clinical characteristic at the onset of symptoms.

Major clinical symptoms (total cases $n=64$ )

\begin{tabular}{lc}
\hline Epileptic seizures & $36 \%(\mathrm{n}=23)$ \\
Headache & $34 \%(\mathrm{n}=22)$ \\
Visual disorders & $11 \%(\mathrm{n}=7)$ \\
Hemiparesis & $9 \%(\mathrm{n}=6)$ \\
Gait instability & $6 \%(\mathrm{n}=4)$ \\
No symptoms & $6 \%(\mathrm{n}=4)$
\end{tabular}

Minor clinical symptoms

Behavioural disorders

Memory loss

Confusion

$5 \%(\mathrm{n}=3)$

Muscle weakness

Spinal cord compression

Attention deficit

Dysphasia

$3 \%(\mathrm{n}=2)$

(VMT), CD99 and S-100 protein and negative for Glial fibrillary acidic protein (GFAP) (28). They are also positive for progesterone receptors but not for estrogens; in fact, the presence of progesterone receptors has been reported to be correlated with a more severe form and recurrences (29). Also, these cells are negative for Calretinin; a highly sensitive but not specific marker for adipocytic tumours. These histopathological features are essential diagnostic elements to differentiate this tumour's typical lipomatosis process from other diagnoses.5 In the presence of evident areas of the tumour lipidisation, the differential diagnosis between lipomatous meningioma and lipoma relies on the immunohistochemical analysis; positivity for EMA, and negativity Type-4 Collagen confirms the diagnosis of lipomatous meningioma (16). EMA and VMT are distinctive markers for meningiomas that reflect epithelial and mesenchymal cells (30); markers of immunoreactivity such as EMA, VMT, S-100, and progesterone receptors confirm the meningothelial differentiation (27). Cases in which both secretory and lipidated cells are present, the hyaline inclusion bodies of the secretory type meningioma result positive for periodic acid Schiff (PAS) stain as well as carcinoembryonic antigen (CEA), with surrounding CK-positive tumour cells (11). The presence of fat tissue is definitively diagnosed with the histological and immunohistochemical examination. Besides, a precise evaluation of the lipomatous meningioma's radiological features is of fundamental importance to characterise the benign nature of such tumour (31). Hypodensity, displayed in CT images, is often associated with cystic degeneration, tumour necrosis or previous haemorrhage (13), while hyperintensity in T1-weighted MRI is frequently associated with lipomas, teratomas or met-haemoglobin (13). 
Macroscopically, the lesions were yellowish, soft, and difficult to differentiate from adipose tissue. The different histological findings of lipomatous meningiomas are described as meningothelial meningiomas with a lipomatous component in $38 \%$ of cases, transitional meningiomas with a lipomatous component in $12 \%(7,25,27,32,33)$, secretory meningioma with a lipomatous component in $8 \%(8-11,34)$, microcystic meningioma with a lipomatous component in $3 \%$ $(7,27)$, and in only one case the histological diagnosis was Chordoid Meningioma with a lipomatous component (7). The meningothelial cell with lipomatous metaplasia exhibited immunoreactivity to Epithelial Membrane Antigen (EMA) in 37 cases $(5,7-10,15,16,23-28,33,35,36)$, and Vimentin in 15 cases $(5,9,10,15,16,23-26,28,35-37)$. Ten meningiomas presented progesterone receptor $(5,6,15,27$, $33,34,37)$, nine meningiomas showed S100- Protein $(11,24$, $26,27,35,36)$, three meningiomas presented $\operatorname{CD} 99(27,37)$, three meningioma showed Cytokeratin $(8,11,34)$, and two cases resulted positive for $\operatorname{CEA}(8,11)$.

\section{Treatment}

Almost all found lesions were located in the supratentorial region (frontal, temporal or parietal lobe), except for 3 cases $(7,32)$, in which the spine was involved. Lattes et al. described a single case of extra-axial meningioma on the orbit (35). The tumours showed a hypodensity signal on CT images, except in two cases $(15,24)$, in which the lesion presented a hyperdense appearance with hypodense foci inside. Depending on the degree of fat component, meningiomas can be seen at CT images as hyperintense or hypointense with hyperintense foci in weighted $\mathrm{T} 1$, and hypo-isointense or hyperintense sequences in T2-weighted sequences. The contrast enhancement, if present, is homogeneous. In this review, all lesions were surgically removed; the partial resection procedures were six, and the total resections were thirty-nine. When the resection was completed, the reported follow-up showed no recurrences.

\section{Prognosis and Results}

Roncaroli et al. estimated the recurrence rate of lipomatous meningioma to be around 17\%, reporting 3 cases of recurrence out of 18 total cases. These 3 cases presented recurrence at 7 , 8 and 24 months. Also, these recurrences were related to cases that had undergone incomplete resection (7). Lipomatous meningiomas are classified as WHO grade I tumours, however, cases in which the tumour characteristics differed from the canonical features have been found. Aage et al. has described a case of lipomatous meningioma with hypercellularity, small cell changes, and a sheathing pattern suggestive of atypical meningioma of WHO grade 2 tumours (38). Sadiya et al. described the case of a recurrent meningioma, which presented characteristics of an atypical type (mitosis $>4 / 10 \mathrm{hpf}$ ), lipomatous type meningioma, and focal papillary features (37). Therefore, it is crucial to correctly identify these features which are related to the aggressive form of the tumour and a higher rate of recurrence (37).

\section{Conclusion}

Upon reviewing the literature, examining the available LM cases descripted, we have collated and presented the typical features that can be useful in correctly identifying this rare type of meningioma. The main clinical characteristics of LM at onset of symptoms are epileptic seizures followed by headache and migraine with or without visual aura. The imaging analysis of the LM cases revealed helpful characteristics to correctly classify and distinguish the lipomatous type meningioma from lesions of different origin, which can present similar density or intensity at MRI sequences, but malignant behaviour. The specific histologic and immune-histological findings have been correlated with the radiological features, which can alone allow earlier identification of the tumour. Regarding the surgical intervention, a partial or not complete resection with residual tumour is associated with a high rate of relapse. In the cases analysed, a complete safe resection "en bloc" of this type of rare tumour is the suggested surgical treatment that has shown a favourable outcome and is associated with a low recurrence rate. Therefore, the accurate identification of LM by the combination of imaging and immune-histological features is essential for the correct choice of surgical treatment.

\section{Conflicts of Interest}

The Authors declare that they have no conflicts of interest in relation to this study.

\section{Authors' Contributions}

Conceptualisation, P.L. G.Z.; methodology, P.L. and G.Z; investigation, P.L., P.F., P.B, G.Z.; resources, A.S.; data curation, P.F and P.B.; writing - original draft preparation, P.L.; writing - review and editing, P.L.; visualisation, R.C., X.L.; supervision, G.F.; funding acquisition, G.F.

\section{Acknowledgements}

This research was funded by the Ministry of Foreign Affairs and International Cooperation of Italy (MAECI) project number CN18GR10.

\section{References}

1 Harter PN, Braun Y and Plate KH: Classification of meningiomasadvances and controversies. Chin Clin Oncol 6(Suppl 1): S2, 2017. PMID: 28595423. DOI: 10.21037/cco.2017.05.02 
2 Kasantikul V and Brown WJ: Lipomatous meningioma associated with cerebral vascular malformation. J Surg Oncol 26(1): 35-39, 1984. PMID: 6427530. DOI: 10.1002/jso.2930260109

3 Bailey P and Bucy PC: The origin and nature of meningeal tumors. Am J Cancer 15: 15-54, 1931. DOI: 10.1158/ajc.1931.15

4 Perry A, Louis DN, Scheithauer BW, Budka $\mathrm{H}$ and von Deimling A: Meningiomas. In: World Health Organization classification of tumours of the central nervous system. Louis DN, Ohgaki H, Wiestler OD, Cavenee WK (eds.). France, IARC, pp. 164-172, 2007.

5 Yüksel MO, Gürbüz MS, Tanrıverdi $\mathrm{O}$ and Özmen SA: Lipomatous meningioma: A rare subtype of benign metaplastic meningiomas. J Neurosci Rural Pract 8(1): 140-142, 2017. PMID: 28149104. DOI: 10.4103/0976-3147.193539

6 Kim L, Huang C, Morey AL and Winder MJ: Intraosseous lipomatous meningioma. Case Rep Neurol Med 2015: 482140, 2015. PMID: 25688309. DOI: $10.1155 / 2015 / 482140$

7 Roncaroli F, Scheithauer BW, Laeng RH, Cenacchi G, AbellAleff $\mathrm{P}$ and Moschopulos M: Lipomatous meningioma: a clinicopathologic study of 18 cases with special reference to the issue of metaplasia. Am J Surg Pathol 25(6): 769-775, 2001. PMID: 11395554. DOI: 10.1097/00000478-200106000-00008

8 Yamada H, Hanada T, Okuda S, Yokota A and Haratake J: Secretory meningioma with lipomatous component: case report. Brain Tumor Pathol 16(2): 77-80, 1999. PMID: 10746964. DOI: 10.1007/BF02478906

9 Matyja E, Naganska E, Zabek M and Jagielski J: Meningioma with the unique coexistence of secretory and lipomatous components: a case report with immunohistochemical and ultrastructural study. Clin Neuropathol 24(6): 257-261, 2005. PMID: 16320819.

10 Patil PR, Warpe BM, Juvekar VH and Manohar V: Meningioma with the unique coexistence of secretory and lipomatous components: A case report with immunohistochemical study. Indian J Pathol Microbiol 60(3): 381-384, 2017. PMID: 28937376. DOI: 10.4103/IJPM.IJPM_123_16

11 Khubrani $\mathrm{R}$ and Al-Dandan S: Two different meningioma variants in the same tumor: a rare histopathological finding. Case Rep Pathol 2019: 8267163, 2019. PMID: 31210995. DOI: $10.1155 / 2019 / 8267163$

12 Taraszewska A and Matyja E: Secretory meningiomas: immunohistochemical pattern of lectin and ultrastructure of pseudopsammoma bodies. Folia Neuropathol 52(2): 141-150, 2014. PMID: 25118899. DOI: 10.5114/fn.2014.43785

13 LeRoux P, Hope A, Lofton S and Harris AB: Lipomatous meningioma - an uncommon tumor with distinct radiographic findings. Surg Neurol 32(5): 360-365, 1989. PMID: 2814788. DOI: 10.1016/0090-3019(89)90140-7

14 Scheithauer BW: Tumors of the meninges: proposed modifications of the World Health Organization classification. Acta Neuropathol 80(4): 343-354, 1990. PMID: 2239146. DOI: 10.1007/BF00307686

15 Gasparinho MG, Ferreira M, Lavrador JP and Livraghi S: Revisiting lipomatous meningioma: a case report and review of an unusual entity. Int J Surg Pathol 23(5): 399-403, 2015. PMID: 25911563. DOI: $10.1177 / 1066896915583695$

16 Bolat F, Kayaselcuk F, Aydin MV, Erdogan B, Ulusan S and Zorludemir S: Lipidized or lipomatous meningioma, which is more appropriate? A case report. Neurol Res 25(7): 764-766, 2003. PMID: 14579797. DOI: 10.1179/016164103101202147
17 Withers T, Klevansky A and Weinstein SR: Lipomeningioma: case report and review of the literature. J Clin Neurosci 10(6): 712-714, 2003. PMID: 14592630. DOI: 10.1016/s09675868(03)00078-X

18 Er U, Gürkanlar D, Kazancı A, Şimşek S and Bavbek M: Lipomatous meningioma: Report of a case and a diagnostic pitfall. Turk Neurosurg 16: 40-43, 2006.

19 Kepes JJ: Lipidized meningothelial tumor cells in "xanthomatous" meningioma express macrophage antigen. J Neuropathol Exp Neurol 53(4): 384-388, 1994. PMID: 8021712. DOI: $10.1097 / 00005072-199407000-00010$

20 Okamoto K, Ito J, Tokiguchi S, Furusawa T, Yoshida S, Tanaka $\mathrm{R}$, Iwanaga $\mathrm{K}$ and Oyanagi $\mathrm{K}$ : Development of fat within a meningioma. Neuroradiology 38(3): 214-216, 1996. PMID: 8741189. DOI: 10.1007/BF00596531

21 Cushing $\mathrm{H}$ and Eisenhardt L: Meningiomas: Their classification, regional behaviour, life history, and surgical end results. Springfield, Illinois, Charles C. Thomas, pp. 785, 1938.

22 Kashimura H, Arai H, Ogasawara K, Beppu T, Kurose A and Ogawa A: Lipomatous meningioma with concomitant acute subdural hematoma - case report - . Neurol Med Chir (Tokyo) 48(10): 466469, 2008. PMID: 18948682. DOI: 10.2176/nmc.48.466

23 Kimiwada T, Motohashi O, Kumabe T, Watanabe M and Tominaga $\mathrm{T}$ : Lipomatous meningioma of the brain harboring metastatic renalcell carcinoma: a case report. Brain Tumor Pathol 21(1): 47-52, 2004. PMID: 15696969 . DOI: $10.1007 /$ BF02482177

24 Carlotti Júnior CG, Colli BO, Chimelli L, Dos Santos AC and Elias Júnior J: Lipoblastic meningioma. Case report. Arq Neuropsiquiatr 56(3B): 661-665, 1998. PMID: 9850767. DOI: 10.1590/s0004-282x1998000400024

25 Jaiswal AK, Mehrotra A, Kumar B, Jaiswal S, Vij M, Behari S and Pal L: Lipomatous meningioma: a study of five cases with brief review of literature. Neurol India 59(1): 87-91, 2011. PMID: 21339670. DOI: 10.4103/0028-3886.76876

26 Grand S, Pasquier BM, Hoffmann DM, Krainik A, Ashraf A, Tropres IM, Dillworth $\mathrm{K}$ and Le Bas JF: Perfusion MR imaging and $1 \mathrm{H}$ spectroscopy: their role in the diagnosis of microcystic and lipomatous meningiomas. J Neuroradiol 37(3): 185-188, 2010. PMID: 19783308. DOI: 10.1016/ j.neurad 2009.08 .008

27 Colnat-Coulbois S, Kremer S, Weinbreck N, Pinelli C and Auque J: Lipomatous meningioma: report of 2 cases and review of the literature. Surg Neurol 69(4): 398-402; discussion 402, 2008. PMID: 17825370. DOI: 10.1016/j.surneu.2006.11.072

28 Mariniello G, Spaziante R, Del Basso De Caro ML and de Divitiis E: An unusual case of lipoblastic meningioma of the falx cerebri. Clin Neurol Neurosurg 102(3): 180-185, 2000. PMID: 10996720. DOI: 10.1016/s0303-8467(00)00094-9

29 Pravdenkova S, Al-Mefty O, Sawyer J and Husain M: Progesterone and estrogen receptors: opposing prognostic indicators in meningiomas. J Neurosurg 105(2): 163-173, 2006. PMID: 17219818. DOI: 10.3171/jns.2006.105.2.163

30 Choi YH, Choi CY, Lee CH, Koo HW and Chang SH: Metaplastic meningioma overspreading the cerebral convexity. Brain Tumor Res Treat 6(2): 97-100, 2018. PMID: 30381925. DOI: 10.14791/btrt.2018.6.e17

31 Fitt GJ, Kalnins R and Mitchell LA: Lipomatous meningioma: characteristic computed tomographic appearance. Australas Radiol 40(1): 84-87, 1996. PMID: 8838898. DOI: 10.1111/j.14401673.1996.tb00354.x 
32 de Eulate-Beramendi SA, Piña-Batista KM and Rial-Basalo JC: Extradural en-plaque spinal lipomatous meningioma: A case report and literature review. Surg Neurol Int 10: 49, 2019. PMID: 31528387. DOI: $10.25259 / \mathrm{SNI}-87-2019$

33 Harmouch T, Colombat M, El Amri A, Feydy A, Kalamarides M, Redondo A and Degott C: Lipomatous meningioma: two case reports. Ann Pathol 25(5): 389-392, 2005. PMID: 16498292. DOI: $10.1016 / \mathrm{s} 0242-6498(05) 80147-6$

34 Liebig T, Hoffmann T, Hosten N, Sander B, van Landeghem F, Stoltenburg-Didinger G and Lanksch WR: Lipomatous secretory meningioma: case report and review of the literature. Neuroradiology 40(10): 656-658, 1998. PMID: 9833895. DOI: $10.1007 / \mathrm{s} 002340050658$

35 Lattes R and Bigotti G: Lipoblastic meningioma: "vacuolated meningioma". Hum Pathol 22(2): 164-171, 1991. PMID: 2001878. DOI: 10.1016/0046-8177(91)90038-q

36 Ohba S, Yoshida K, Akiyama T, Ikeda E and Kawase T: Lipomatous meningioma. J Clin Neurosci 14(10): 1003-1006, 2007. PMID: 17240148. DOI: 10.1016/j.jocn.2006.03.011
37 Sadiya N, Halbe S, Ghosh M and Ghosh S: Rare intracranial recurrent meningioma with unique coexisting atypical, papillary and lipomatous component: Case report and review of literature. World Neurosurg 133: 216-220, 2020. PMID: 31610245. DOI: 10.1016/j.wneu.2019.09.151

38 Aage BM, Temkar P, Chemate S and Mangaleswaran B: Coexistence of atypical meningioma, intratumoral lipometaplasia and extensive hyperostosis of calvarium: a rare entity. World Neurosurg X 1: 100001, 2018. PMID: 31251308. DOI: 10.1016/ j.wnsx.2018.100001
Received August 10, 2021

Revised September 18, 2021 Accepted September 20, 2021 